\title{
On the generation and role of eddy variability in the central North Atlantic Ocean
}

\author{
Aike Beckmann, ${ }^{1}$ Claus W. Böning, Bernd Brügge, and Detlef Stammer ${ }^{2}$ \\ Institut für Meereskunde, Kiel, Germany
}

\begin{abstract}
Sources of near-surface oceanic variability in the central North Atlantic are identified from a combined analysis of climatology, surface drifter, and Geosat altimeter data as well as eddy-resolving $\frac{1}{3}^{\circ}$ and $\frac{1}{6}^{\circ}$ Community Modeling Effort North Atlantic model results. Both observational and numerical methods give a consistent picture of the concentration of mesoscale variability along the mean zonal flow bands. Three areas of high eddy energy can be found in all observational data sets: the North Equatorial Current, the North Atlantic Current, and the Azores Current. With increasing horizontal resolution the numerical models give a more realistic representation of the variability in the first two regimes, while no improvement is found with respect to the Azores Current Frontal Zone. Examination of the upper ocean hydrographic structure indicates baroclinic instability to be the main mechanism of eddy generation and suggests that the model deficiencies in the Azores Current area are related to deficiencies in the mean hydrographic fields. A linear instability analysis of the numerical model output reveals that instability based on the velocity shear between the mixed layer and the interior is also important for the generation of the mid-ocean variability, indicating a potential role of the mixed layer representation for the model. The $\frac{1}{6}^{\circ}$ model successfully simulates the northward decrease of eddy length scales observed in the altimeter data, which follow a linear relationship with the first baroclinic Rossby radius. An analysis of the eddy-mean flow interaction terms and the energy budget indicates a release of mean potential energy by downgradient fluxes of heat in the main frontal zones. At the same time the North Atlantic Current is found to be supported by convergent eddy fluxes of zonal momentum.
\end{abstract}

\section{Introduction}

Numerous field studies in the North Atlantic have revealed the geographically highly inhomogeneous distribution of near-surface mesoscale variability in the ocean: maxima occur at the western boundaries, in the tropics, and along the main frontal systems, while the remainder of the ocean is much more "quiet." Climatological maps of the temperature and velocity variance have been compiled from extensive expendable bathythermograph (XBT) data sets [Dantzler, 1977; Emery, 1983] and surface drifter data [Richardson, 1983; Krauss and Käse, 1984]. Recently, satellite altimetry provided repeated quasi-simultaneous observations of the sea surface height (SSH) with global coverage, a powerful tool for investigating the space and time scales of the oceanic surface fields [LeTraon et al., 1990; Stammer and Böning, 1992].

At the same time, basin-wide eddy-resolving numerical modeling has created new possibilities for the examination and interpretation of ocean dynamics [Bryan and Holland, 1989; Böning et al., 1991a; Semtner and Chervin, 1992; Beckmann et al., 1994]. Motivated by the availability of the

\footnotetext{
${ }^{1}$ Now at Alfred-Wegener-Institute for Polar and Marine Research, Bremerhaven, Germany.

${ }^{2}$ Now at Department of Earth, Atmospheric and Planetary Sciences, Massachusetts Institute of Technology, Cambridge.

Copyright 1994 by the American Geophysical Union.

Paper number 94JC01654.

0148-0227/94/94JC-01654\$05.00
}

detailed observational data sets and an improved realism in eddy kinetic energy (EKE) levels in an eddy-resolving general circulation model (EGCM; see section 2), we present a reconsideration of the distribution, sources, and role of EKE in the open ocean.

The aim of this paper is to intercompare the different observational results and to relate the numerical model results to the observed fields (section 3), concentrating on the near-surface eddy kinetic energy (for example EKE at $100 \mathrm{~m}$ depth). We shall focus on the central North Atlantic (between $20^{\circ} \mathrm{W}$ and $40^{\circ} \mathrm{W}$ and from the equator to $60^{\circ} \mathrm{N}$ ) to study the meridional variation of eddy energy and its relation to the mean hydrographic structures and flow field. Eddy length scales, an important statistical property of the observed and simulated variability, are investigated and intercompared in detail, and improvements by increased horizontal resolution in a simulation of the North Atlantic circulation are evaluated (section 4). The analysis of generation mechanisms in section 5 includes upper ocean fields from climatology and the models. Results from a linear stability analysis and eddy-mean flow interaction terms are presented. The role of turbulent fluxes is considered. Finally, section 6 offers summarizing conclusions.

\section{Eddy-Resolving Modeling}

Previous attempts to simulate the observed variability in numerical models were limited either to simplified physical systems (the quasi-geostrophic (QG) approximation) and geometries or, in case of primitive equation (PE) models, to 
Table 1. Overview of Kiel-CME Experiments

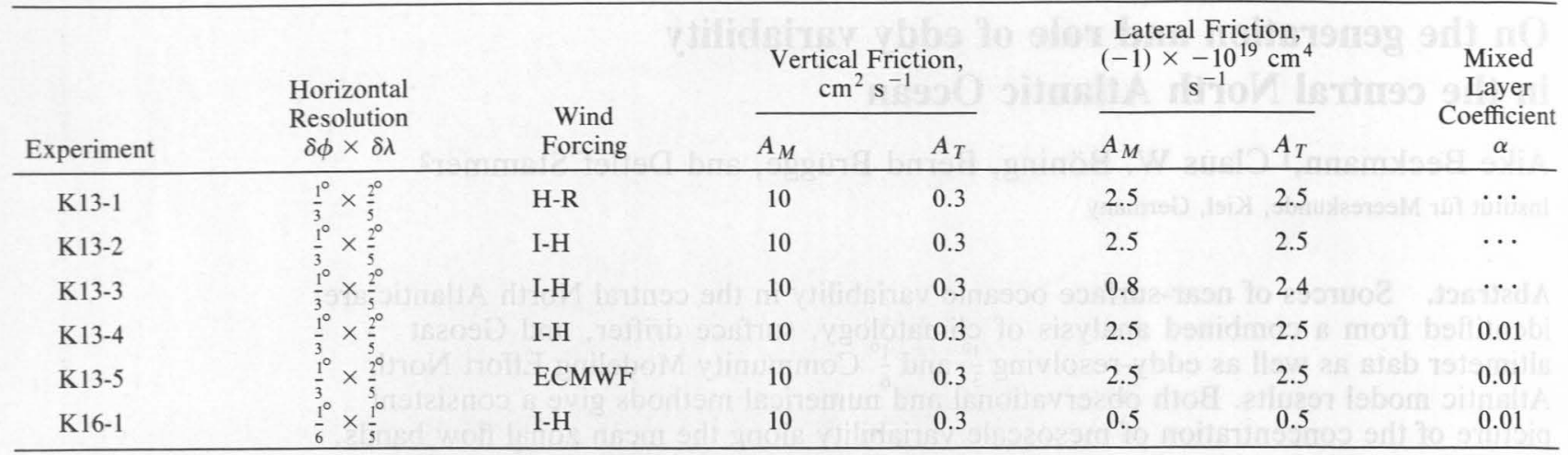

H-R and I-H indicate the use of Hellerman and Rosenstein [1983] and Isemer and Hasse [1987] monthly mean wind forcing, respectively; ECMWF denotes daily mean wind stress from the European Centre for Medium-Range Weather Forecasts. Subscripts $M$ and $T$ refer to the momentum and tracer viscosity and diffusivity coefficients, respectively. The mixed layer coefficient $\alpha$ is the percentage of wind energy used for the deepening of the mixed layer.

a relatively coarse and viscous regime. Both insufficient horizontal resolution and the related large lateral diffusion, necessary to parameterize the sub-grid-scale processes, led to a level of variability far smaller than observed. An earlier study based on a series of eddy-resolving simulations with a PE model using an idealized geometry (the so-called "box model") and a single-state variable (density) gave an indication of the responsible generation mechanisms and demonstrated the sensitivity to model resolution and frictional parameterization [Böning and Budich, 1992]. Because of the idealized geometry and topography, however, a relation between the model features and the observed phenomena could not be easily established.

While deficiencies of the box models could be explained by the obvious limitations introduced by the above mentioned simplifications, the Community Modeling Effort (CME) [Bryan and Holland, 1989] model should not suffer from these problems. It was initiated as an attempt to simulate the basin-wide ocean circulation with a high degree of realism (with respect to geometry, topography, physics, and forcing), to explore the sensitivity to certain model parameters (frictional coefficients, wind forcing, and resolution), and, most importantly, to address the important question about the role of mesoscale eddies in the circulation which is not directly accessible by measurements.

Detailed descriptions of the model and the strategy behind the sensitivity experiments can be found in the work of Böning et al. [1991a, b], Beckmann et al. [1994], and Bryan et al. [1994]. Some important points, however, will be reiterated here briefly. The CME experiments make use of a PE model [Bryan, 1969; Cox, 1984] in realistic North Atlantic $\left(15^{\circ} \mathrm{S}\right.$ to $\left.65^{\circ} \mathrm{N}\right)$ geometry and topography. The initial data for temperature and salinity are taken from the Levitus [1982] data set. The basin is artificially closed at the northern and southern zonal walls, using restoring zones of a few grid points. Labrador Shelf Water formation and Mediterranean Water input are parameterized in a similar way. The basic calculation with $\frac{1^{\circ}}{3} \times \frac{2^{\circ}}{5}$ resolution and 30 nonequidistant levels is a spin-up run of 20 model years performed at the National Center for Atmospheric Research (NCAR) [Bryan and Holland, 1989] with Hellerman and Rosenstein [1983] wind forcing. The final state of this spin-up serves as starting point for various further investigations on the model sensitivity to lateral and vertical diffusion and viscosity, wind climatology, and mixed layer parameterization (see Table 1) which have been carried out for several years each. The wind forcing for most of the Kiel runs is interpolated linearly in time between monthly mean values of Isemer and Hasse [1987] climatology. Experiment K13-5 uses daily European Centre for Medium-Range Weather Forecasts (ECMWF) winds and will be treated in more detail in a separate study. For the first four experiments (K13-1 through K13-4) the eddy variability was only insignificantly affected by the applied modifications. In particular, the addition of a simple, Kraus-Turner type mixed layer model did not change the strength and distribution of eddy fields significantly.

In this study we shall use model output from a basic $\frac{1}{3}^{\circ}$ case (K13-4) and from a case with increased $\frac{1^{\circ}}{6}$ resolution (K16-1).

\section{Spatial Distribution of Mid-Ocean Variability}

A first comprehensive presentation of the distribution of eddy energy was obtained from the historical data maps by Dantzler [1977] and Emery [1983]. The compilation of XBT data (temperature fluctuations $T_{R M S}$ at $400 \mathrm{~m}$ depth as a measure of the eddy potential energy) exhibits a band of large values in the Boundary Current System and the Extension Area, as well as the North Atlantic Current. This area of increased variability branches at $45^{\circ} \mathrm{W}$ into a northward and a southward band associated with the North Atlantic Current (NAC) at about $50^{\circ} \mathrm{N}$ and the Azores Current (AC) along $35^{\circ} \mathrm{N}$. The remainder of the subtropical gyre is relatively "quiet." To the south, there is a general equatorward increase in eddy potential energy (EPE) related to the North Equatorial Current (NEC).

More recent investigations make use of altimeter and Lagrangian float data. LeTraon et al. [1990] present maps of objectively mapped SSH anomalies from Geosat and EKE estimates from the cross-track velocity component (assuming spatial isotropy of the mesoscale eddy field). While the eastward penetration of EKE in the NAC and the increased values of variability at $35^{\circ} \mathrm{N}$ found in the climatology are clearly visible in SSH fields, the latter structure is less pronounced in the derived EKE fields. The study of LeTraon et al. [1990] also compares the altimeter results with the drifter analysis by Richardson [1983], with qualitatively similar results. The analysis of an earlier subset of the drifter 
data from the Kiel "Warmwatersphere" program by Krauss and Käse [1984] also showed the concentration of eddy energy along the NAC but only a slight indication of higher kinetic energy at $35^{\circ} \mathrm{N}$, probably because of insufficient data coverage in that area.

Quantitative conclusions from these earlier surface drifter data sets are difficult, since the depth of the drogues differed and the number of drifters in the central and eastern North Atlantic was relatively small, not allowing, for example, a correction for drogue loss. The importance of separating drifter data with and without drogue was demonstrated by Brügge and Dengg [1991]. Their method of identifying and eliminating data from drifters without drogues was recently applied by $\mathrm{B}$. Brügge (Near-surface mean circulation and kinetic energy in the central North Atlantic from drifter data, submitted to Journal of Geophysical Research, 1994) (hereinafter referred to as Brügge, submitted manuscript, 1994) to the whole Kiel drifter data set, which now includes 35,000 buoy days between 1981 and 1990 and can be considered the most extensive drifter data set for the central North Atlantic currently available. Brügge (submitted manuscript, 1994) shows that the elimination of undrogued buoys significantly reduces the influence of wind effects on the trajectories. In the corrected data set, which primarily reflects the signal of the geostrophic interior, there are clear maxima related to the NAC and $\mathrm{AC}$, extending as far east as $15^{\circ} \mathrm{W}$. We shall use these drifter data below (Figure 1) for comparison with Geosat and model results.

A good impression of the banded structure of variability in the eastern basin and a quantitative comparison of different data sets can be obtained from a meridional section through the basin. Figure 1 shows results from Geosat and drifter data and solutions from two versions of the CME model along $30^{\circ} \mathrm{W}$. All EKE data are averaged zonally from $28^{\circ}$ to $32^{\circ} \mathrm{W}$ (or $25^{\circ}-35^{\circ} \mathrm{W}$, with very similar results). Figure 1a shows EKE from the Kiel drifter data set. If all (i.e., drogued and undrogued) data are included, maximum values are 520 and $330 \mathrm{~cm}^{2} \mathrm{~s}^{-2}$ for the NAC and AC regions, respectively (Figure 1a). The minimum between these peaks lies at about $200 \mathrm{~cm}^{2} \mathrm{~s}^{-2}$. If undrogued buoys are eliminated, the EKE values are substantially smaller. Because the variability is more strongly reduced outside the main frontal zones, the concentration of EKE at the main fronts becomes even more pronounced. EKE values for the NAC and AC are 450 and $180 \mathrm{~cm}^{2} \mathrm{~s}^{-2}$, respectively, at this longitude.

Results from the Geosat altimeter are presented in Figure 1b. Quantitative statements depend to some degree on choices made for horizontal smoothing procedures. Applying a $2^{\circ} \times 2^{\circ}$ horizontal averaging and a Lanczos low-pass filter, the along-track cutoff scale determines the exact shape of the variability distribution. (For a more detailed description of the altimeter data processing and error levels, see Stammer and Böning [1992]). In Figure 1b, curves are displayed for both 40 - and $100-\mathrm{km}$ decorrelation scale (the latter was also used by LeTraon et al. [1990]). Again, high-energy bands stand out along the NAC and $\mathrm{AC}$, and there is also an indication of enhanced variability in the NEC regions. The minima of EKE between these bands are not smaller than $100 \mathrm{~cm}^{2} \mathrm{~s}^{-2}$, which to some degree can be related to data uncertainties. The use of a larger filtering scale generally gives smaller variability and tends to reduce the maximum in the NAC. The "smoothing effect" is smallest in the AC, where a fairly robust EKE value of 250
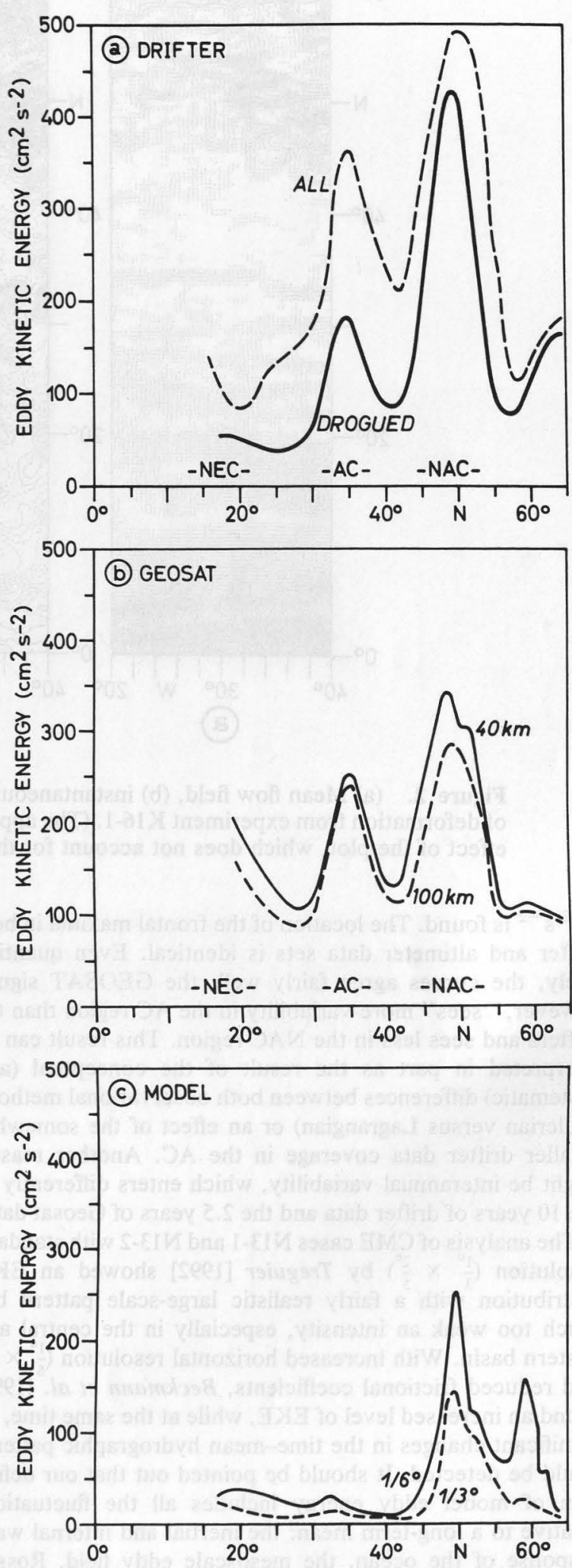

Figure 1. Meridional dependence of near-surface EKE at $30^{\circ} \mathrm{W}$ (a) from surface drifters for all data (dashed line) and drogued drifters only (solid line), (b) from Geosat EKE analysis for decorrelation scale of $100 \mathrm{~km}$ (dashed line) and $40 \mathrm{~km}$ (solid line), and (c) from the $\frac{1}{3}^{\circ}$ model (K13-4) (dashed line) and the $\frac{1}{6}^{\circ}$ model (K16-1) (solid line) [from Beckmann et al., 1994]. 


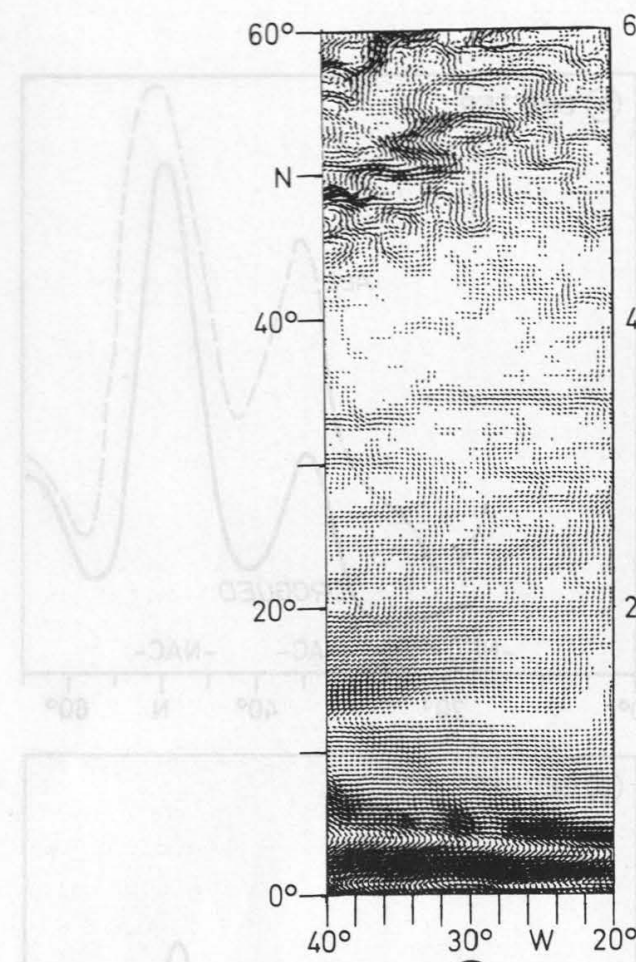

(2)

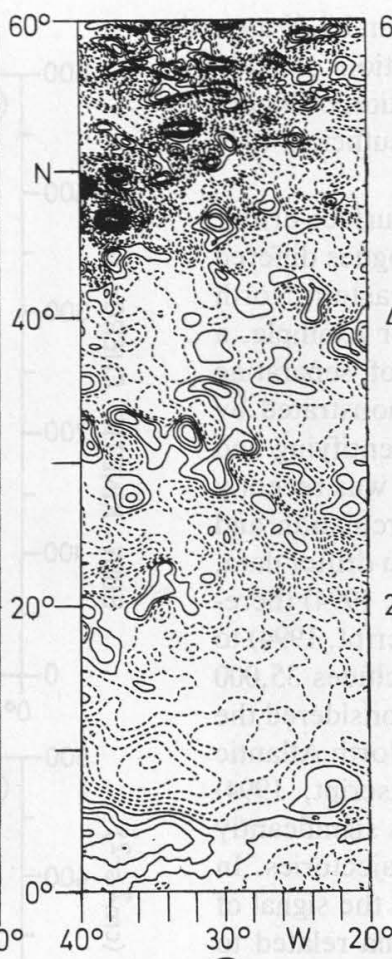

(b)

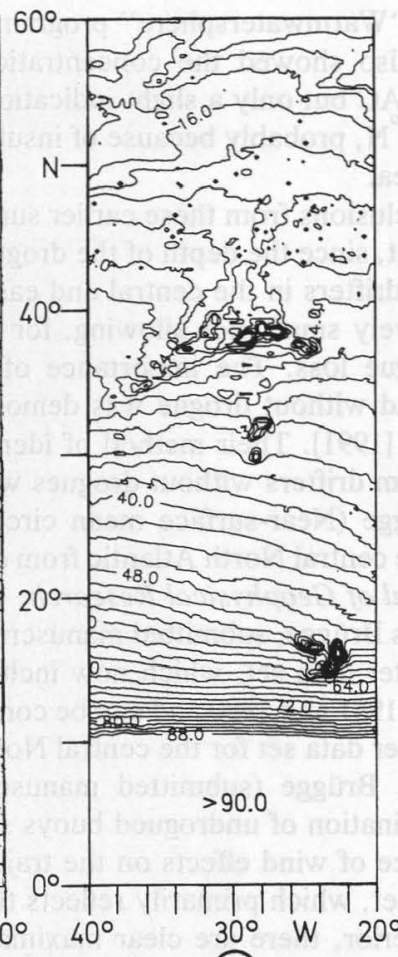

(c)

Figure 2. (a) Mean flow field, (b) instantaneous sea surface height anomaly field, and (c) Rossby radius of deformation from experiment K16-1. (The apparent anisotropy of the eddies north of $45^{\circ} \mathrm{N}$ is an artificial effect of the plot, which does not account for the convergence of the meridians.)

$\mathrm{cm}^{2} \mathrm{~s}^{-2}$ is found. The location of the frontal maxima in both drifter and altimeter data sets is identical. Even quantitatively, the curves agree fairly well; the GEOSAT signal, however, "sees" more variability in the AC region than the drifters and sees less in the NAC region. This result can be interpreted in part as the result of the conceptual (and systematic) differences between both observational methods (Eulerian versus Lagrangian) or an effect of the somewhat smaller drifter data coverage in the AC. Another reason might be interannual variability, which enters differently in the 10 years of drifter data and the 2.5 years of Geosat data.

The analysis of CME cases N13-1 and N13-2 with standard resolution $\left(\frac{1^{\circ}}{3} \times \frac{2^{\circ}}{5}\right)$ by Treguier [1992] showed an EKE distribution with a fairly realistic large-scale pattern but much too weak an intensity, especially in the central and eastern basin. With increased horizontal resolution $\left(\frac{1}{6}^{\circ} \times \frac{1^{\circ}}{5}\right)$ and reduced frictional coefficients, Beckmann et al. [1994] found an increased level of EKE, while at the same time, no significant changes in the time-mean hydrographic patterns could be detected. It should be pointed out that our definition of model eddy energy includes all the fluctuations relative to a long-term mean: the inertial and internal wave response of the ocean, the mesoscale eddy field, Rossby waves, the seasonal signal, and interannual fluctuations. In some regions, one of these effects may dominate (e.g., the seasonal cycle in the tropics), but no attempt was made here to separate the relevant time scales. For the comparisons we focus on a level $(91 \mathrm{~m})$ below the mixed layer which may be regarded as representative of the upper ocean and appropriate for comparison with drifter and altimetric observations. The horizontal distribution of EKE in this layer is displayed and discussed by Beckmann et al. [1994]. For large areas, EKE values do not exceed $10 \mathrm{~cm}^{2} \mathrm{~s}^{-2}$ for the $\frac{1^{\circ}}{3}$ model. With increased resolution the background level of EKE in the whole basin lies between 10 and $30 \mathrm{~cm}^{2} \mathrm{~s}^{-2}$.

Finally, Figure 1c shows numerical results from two versions of the CME model. The absolute values in Figure 1c are sensitive to the zonal averaging interval, because $30^{\circ} \mathrm{W}$ is near the maximum eastward position of the NAC, but the general structure is representative of the central North Atlantic. The most striking difference between model and observations is the severe underrepresentation of the AC. Aside from this fundamental deficiency of all model runs, the $\frac{1^{\circ}}{6}$ model is in much better agreement with the observed position and amplitude of the NAC.

In summary, the observations as well as the numerical solutions indicate a pronounced concentration of eddy energy along the main (zonally oriented) fronts in the central North Atlantic. In the subsequent sections we shall use the model results to further examine the kinematics of the eddy field and study its generation and dynamical role.

\section{Statistical Properties of the EKE Field: Eddy Length Scales}

We begin our investigation of the generation processes with a more detailed look at the properties of the fluctuating fields. Figure 2 is intended to give an impression of the near-surface time-mean flow, the sea surface height anomaly (relative to a 1-year mean), and the Rossby radius between $20^{\circ} \mathrm{W}$ and $40^{\circ} \mathrm{W}$ north of the equator for the $\frac{1^{\circ}}{6}$ model. This area was chosen because it is far away from real (west, east) 
and artificial (north, south) boundaries. Strong mean flows can be seen in the tropical ocean (Figure 2a), where zonal bands prevail, and north of $45^{\circ} \mathrm{N}$, where the eddy field produces local, partly nonzonal jets. The midlatitudes exhibit weak zonal bands of eastward flow. The eddy field in Figure $2 b$ shows a northward decrease of horizontal scales, but it also suggests the existence of three different regimes (roughly corresponding to different levels of mean and fluctuating energy): a long wave regime in the tropical ocean, a weak eddy field in midlatitudes (where the Azores Current Frontal Zone (ACFZ) is missing), and a highly energetic subpolar front region. This subdivision, however, does not correspond to the local Rossby radii, plotted in Figure 2c. Their variation is relatively uniform across the subdomain, mainly a result of the smooth latitudinal change of the Coriolis parameter.

Stammer and Böning [1992] have presented an analysis of eddy correlation scales from Geosat data and the $\frac{1}{3}^{\circ} \mathrm{CME}$ model (K13-2). They show that extratropical along-track eddy scales (i.e., mainly oriented in meridional direction) as derived from SSH fields are highly correlated with $R_{1}$, the first baroclinic Rossby radius of deformation, as taken from Emery et al. [1984]. A similar relationship had previously been observed for local ensembles of eddies in selected areas, for example, at the "Mode" and "Tourbillon" sites (see, for example, Mercier and Colin de Verdiere [1985]). For the Geosat data a statistical relationship between the meridional scale $L_{\phi}\left(L_{o}\right.$ in Stammer and Böning's [1992] notation) and $R_{1}$ of the form $L_{\phi}=a R_{1}+$ $b$ was derived with $a=2.2$ and $b=79 \mathrm{~km}$. SSH eddy scales in the $\frac{1}{3}^{\circ}$ model proved to be in good agreement with the observations in the tropics and subtropics, despite the severe underestimation of the EKE level. They were systematically larger than the observed scales at higher latitudes, however, where $R_{1}$ is not well resolved by the model grid $\left(>30^{\circ} \mathrm{N}\right)$. Consequently, one could expect a more realistic representation of eddy scales equatorward of $40^{\circ} \mathrm{N}$ for the $\frac{1}{6}^{\circ}$ model.

The higher-resolution results, indeed, fit nicely into this picture, although in a somewhat unexpected way (Figure 3). Instead of extending the area of close correspondence to the north, the meridional scales are systematically (but not significantly in a statistical sense) smaller than the observed ones. However, they decrease with latitude at very much the same rate as the observations, and a linear relationship with $R_{1}$ can be fitted through the model data between $10^{\circ}$ and $60 \mathrm{~N}$ (Figure 4a). It has to be noted that in this study the more appropriate values of $R_{1}$ from the model (see Figure $2 c$ ) are used for comparison with the model length scales. The deviation of $R_{1}$ in the model from their climatological values (e.g., $R_{1}$ is about $50 \%$ larger in the model than for climatology in the region north of $50^{\circ} \mathrm{N}$ ) is noteworthy in its own right. This must be due to changes in the upper ocean water mass characteristics during the 25 years of integration. Part of the deviation of $L_{\phi}$ from the Geosat values found in the $\frac{1^{\circ}}{3}$ model at higher latitudes has to be regarded as an effect of the different $R_{1}$ in the model.

Because isotropy cannot be assumed a priori, a separate look at the zonal length scales is also provided in Figure $4 \mathrm{a}$ with similar results. The largest deviations from a linear correlation occur between $30 \mathrm{~N}$ and $40 \mathrm{~N}$, a further indication of the ACFZ deficiencies. The questions of isotropy were addressed in a study of the sea surface temperature field by Krauss et al. [1990]. The model results are generally consistent with the observations. Moderate $(<25 \%)$ devia-

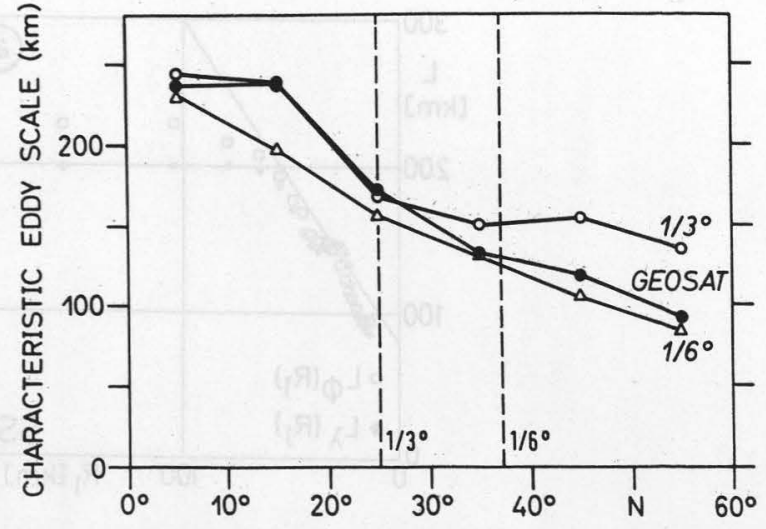

Figure 3. Meridional scales and Rossby radius derived from SSH as a function of latitude. The Geosat results are compared to the numerical experiments K13-4 and K16-1. The vertical lines indicate the

tions from isotropy exist (Figure $4 a^{\prime}$ ) for most latitudes. In the ACFZ region, zonal scales are larger than meridional scales, but in the southern part of the subtropical gyre the ratio is inverted. The latter should be expected for wave disturbances on the broad unstable westward flow in that region.

Several other $\frac{1}{6}^{\circ}$ model variables are used to generalize the SSH results. The dependence of length scales from the stream function and middepth temperature fields are summarized in Figures $4 \mathrm{~b}$ and $4 \mathrm{c}$. Not surprisingly, the typical length scales of the stream function field (Figure 4b) are found to be larger than the SSH scales. The obvious correlation of external mode zonal scales with $R_{1}$ is an interesting property of the eddy field, indicating a close connection between internal and external flow. The model stream function anomalies are clearly nonisotropic (Figure 4b'). A reliable picture of the internal mode eddy scales can be expected from an analysis of the temperature deviation in the main thermocline (say $1000 \mathrm{~m}$ ), where the maximum of the temperature anomaly of first mode baroclinic waves occurs, or the velocity fields at the surface just below the mixed layer to exclude the influence of the surface forcing. The main thermocline temperature scales (Figure $4 \mathrm{c}$ ) are most indicative of a dominance of the first baroclinic mode. In particular, the extratropical zonal scales are directly proportional to $R_{1}$ with a correlation coefficient of $r=0.97$. The subsurface velocity scales (not shown) are generally smaller and characterized by an anisotropy $L_{\phi} / L_{\lambda} \simeq 0.67$ for zonal velocities and $L_{\phi} / L_{\lambda} \simeq 1.50$ for meridional velocities. This is consistent with a corresponding isotropic dynamic height field and in good agreement with the findings of Arhan and Colin de Verdiere [1985].

$\mathrm{SSH}$ scales are generally much smaller than the stream function scales but of the same order as the first internal mode scales. The offset in the SSH scales must therefore be seen as a measure of the influence of the external mode on the surface elevation. It is difficult, however, to quantify the relative contributions. It should also be pointed out that the model results cannot readily be taken as representative of the situation everywhere in the central North Atlantic, because the model deficiencies in the AC and NAC areas could also affect the partition between the vertical modes.

South of $20^{\circ} \mathrm{N}$ the zonal temperature variability scales 

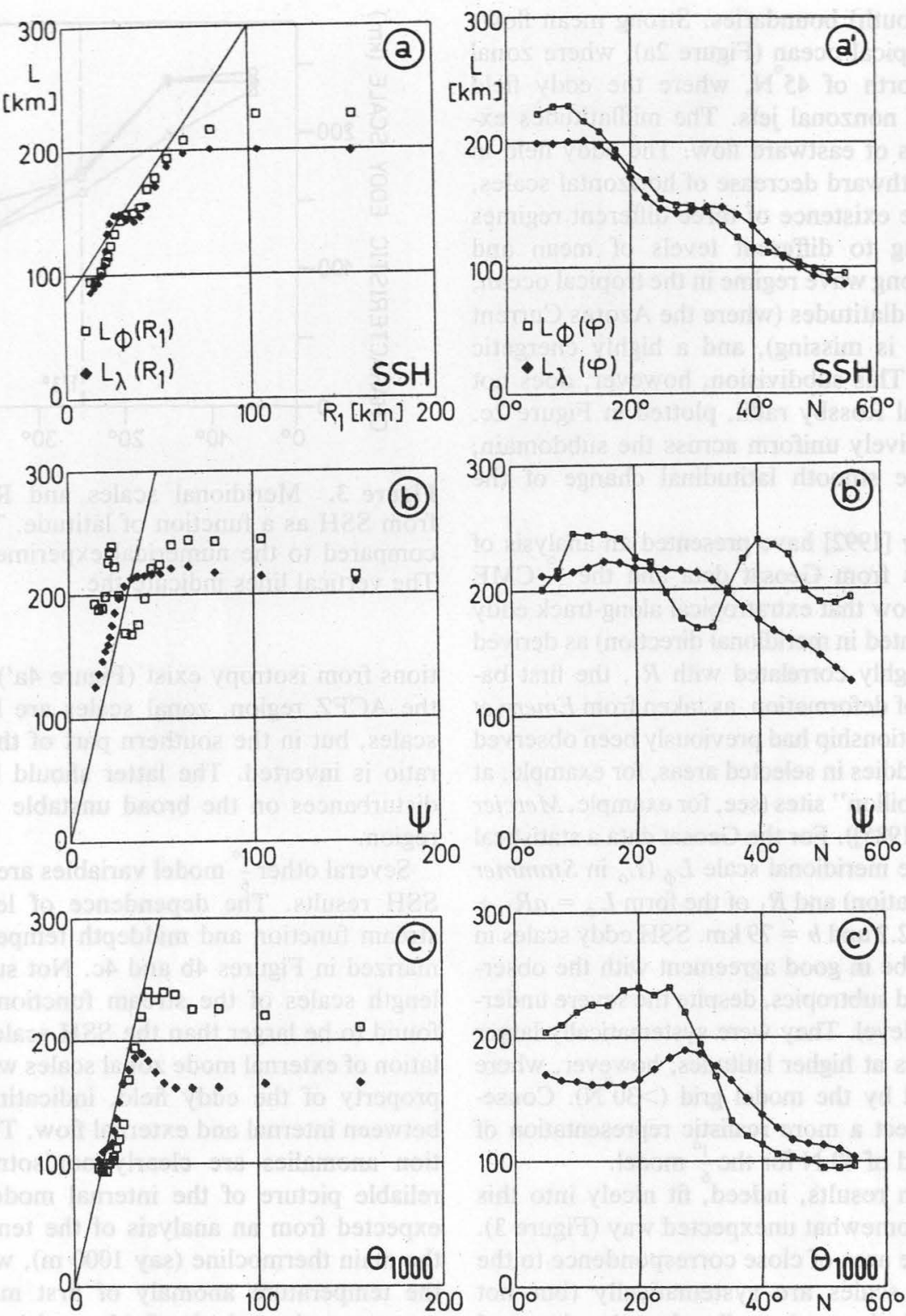

Figure 4. Eddy length scales in the $\frac{1}{6}^{\circ}$ model (experiment K16-1) as a function of local first Rossby radius $R_{1}$ and as a function of latitude: (a)-(a') derived from the SSH anomaly field, with the linear correlation from Geosat data added as a reference in Figure $4 a$; $(b)-\left(b^{\prime}\right)$ derived from the stream function anomaly field; and (c)-(c') derived from the temperature anomaly field at $1000 \mathrm{~m}$ depth. The straight lines in Figures $4 \mathrm{~b}$ and $4 \mathrm{c}$ show a direct proportionality with $2 \pi R_{1}$.

(Figure $4 c^{\prime}$ ) indicate a significant contribution from the second baroclinic mode. The importance of higher vertical modes in midlatitudes and high-latitudes cannot be estimated from the model fields, since even the $\frac{1}{6}^{\circ}$ model does not at all resolve the corresponding horizontal scales. The observations, however, suggest that higher vertical modes are not important in those areas.

\section{EKE Generation Processes}

\subsection{The Hydrographic Structure} in the Central North Atlantic

Motivated by the distinct concentration of EKE along the mean climatological frontal zones, it seems reasonable to assume that a strong interdependence exists between the increased variability and the frontal nature of the NAC and AC. That is, the variability could be generated by instabilities of the mean front and at the same time maintain its structure by feeding back into the mean flow.

The large-scale hydrographic structure and conditions for baroclinic instability $(\mathrm{BCI})$ have previously been examined by McDowell et al. [1982] and Keffer [1985]. Baroclinic instability requires a change in sign of the meridional gradient of potential vorticity

$$
q_{o}=-\left(\zeta_{o}+f\right)(d \bar{\rho} / d z)
$$

somewhere in the vertical (see, for example, Charney and Stern [1962]). While the distribution of the large-scale (low Rossby number) potential vorticity $q_{o}=-f d \bar{\rho} / d z$ (from hydrographic data, ignoring the contribution from relative 
vorticity) only reveals the areas between $10^{\circ} \mathrm{N}$ and $30^{\circ} \mathrm{N}$ in the subtropical gyre as potentially unstable [McDowell et al., 1982; Keffer, 1985], the higher-resolution Robinson-BauerSchroeder (RBS) atlas [Robinson et al., 1979] provides more details of the midlatitude $q_{o}$ structure [Stammer and Woods, 1987]. A meridional section of late winter potential vorticity and density is depicted in Figure 5a. Several regions can be identified where the necessary condition for instability is satisfied, at least during part of the year (late winter/early spring). In addition to the NEC region, one such area lies in the upper thermocline between $50 \mathrm{~N}$ and $55^{\circ} \mathrm{N}$, the location of the NAC. A strikingly similar structure can be found at the mean position of the ACFZ at $35^{\circ} \mathrm{N}$, suggesting that the reason for the underrepresentation of the Azores Front variability in the models is related to the hydrographic situation (density and potential vorticity fields) in that region. Compared to the RBS atlas (Figure 5a), the meridional density gradient in the $\mathrm{AC}$ area is too weak, and an expression of the sharp frontal zone of the AC in the upper ocean is missing in the model (Figure 5b). Consequently, the potential vorticity does not exhibit the necessary structure for baroclinic instability. It is important to note that no significant changes with increased resolution occur in this area, suggesting that model features other than horizontal resolution must be responsible for this deficiency.

\subsection{Shear Mode Instability in the Model}

The necessary condition for instability as inferred from the $q_{o}$ structure does not tell us about the preferred (zonal) scales of the instability and the related growth rates. In order to further investigate this issue, vertical shear modes as derived from QG theory are computed for the mean zonal flow and density profiles, averaged over $1{ }^{\circ}$ meridionally and between $25^{\circ} \mathrm{W}$ and $35^{\circ} \mathrm{W}$. Linear stability is evaluated from the eigenvalue problem (see, for example, Gill et al. [1974] and Beckmann [1988]) for $F(z)$,

$$
\begin{aligned}
\omega\left[-k^{2} F+\left(\frac{f^{2}}{N^{2}} F_{z}\right)_{z}\right]= & {\left[\beta-u_{o y y}-\left(\frac{f^{2}}{N^{2}} u_{o z}\right)\right]_{z} F } \\
& +u_{o} k\left[-k^{2} F+\left(\frac{f^{2}}{N^{2}} F_{z}\right)_{z}\right]
\end{aligned}
$$

with $N^{2}=\left(g / \rho_{o}\right)(d \bar{\rho} / d z)$, subject to the boundary conditions $F_{z}=0$ at the surface and the bottom. Variable $f$ is the local Coriolis parameter, and $u_{o}$ the zonal mean flow. Solutions are complex frequencies $\omega=\omega_{r}+i \omega_{i}$ where the imaginary part represents the growth rate of unstable waves. The system is solved for wavelengths $k^{-1}$ between 10 and $1000 \mathrm{~km}$.

Figure 6a shows the growth rates as a function of latitude and zonal wavelength, measured in grid spacings. The results are surprising: using the above inviscid equation, every single profile between the equator and $60^{\circ} \mathrm{N}$ proves to be unstable to wavelengths smaller than roughly $100 \mathrm{~km}$ with increasing growth rates toward smaller scales (Figure 6a). The largest growth rates can be found in the tropics, but certain extratropical latitudes $\left(18^{\circ}-20^{\circ} \mathrm{N}, 55^{\circ}-60^{\mathrm{N}}\right)$ also show impressive maxima. At the limit of numerical resolution $(2 \Delta x)$ we find perturbation energy doubling times of typically less than 4 days (with the absolute maximum of 1 day near the equator).
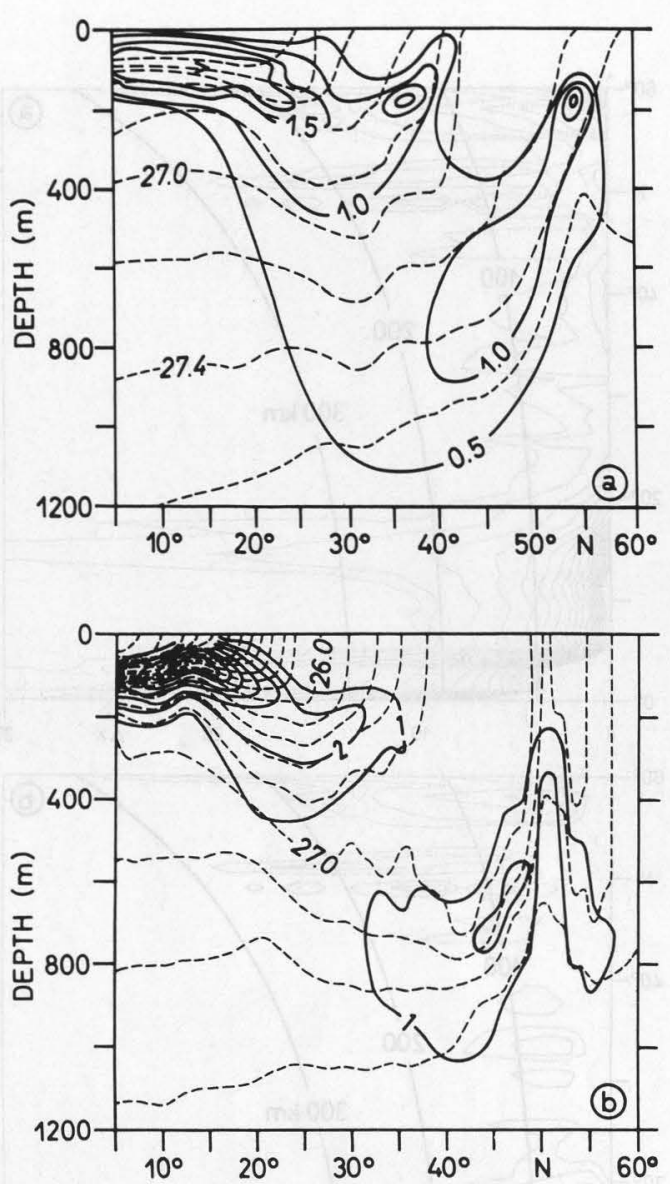

Figure 5. Meridional section of density (dashed lines) and potential vorticity (contour interval $10^{-10} \mathrm{~m}^{-1} \mathrm{~s}^{-1}$ ) along $30^{\circ} \mathrm{W}$ in the upper $1200 \mathrm{~m}$ of the ocean: (a) RBS atlas climatology and (b) $\frac{1}{3}^{\circ}$ model (K13-4) [from Böning and Budich, 1992].

If, in addition, dissipative processes are considered in the analysis, the occurring instability will be restricted to certain zonal wave bands, since the growth of unstable waves has to compete with the damping process. Using the $\frac{1}{6}^{\circ}$ model coefficient of $5 \times 10^{10} \mathrm{~m}^{4} \mathrm{~s}^{-1}$, the inclusion of biharmonic lateral friction causes many of the smaller scales to be stabilized. However, the growth rate diagram still indicates potential instability in many latitudes (Figure 6b). Note in particular the instability between $30^{\circ} \mathrm{N}$ and $40^{\circ} \mathrm{N}$.

The reason for these ubiquitous instabilities is identified to be the velocity shear below the mixed layer which causes a very small scale instability with a corresponding vertical penetration of only a few hundred meters. The vertical structure of the unstable shear modes is an exponential decay with depth from the maximum at the surface, as observed in the EKE fields as well. In an attempt to exclude the effects of the velocity shear below the mixed layer, the two uppermost layers (down to $72 \mathrm{~m}$ ) are excluded from the eigenvalue problem. The result is an almost complete elimination of instability, except for the region north of $55^{\circ} \mathrm{N}$ (Figure 6c).

In contrast to our expectations, the reversal of internal $q_{o}$ gradients is not the only cause for the occurrence of BCI. A large part of the variability in the model seems to originate near the surface, affecting the interior of the ocean only 

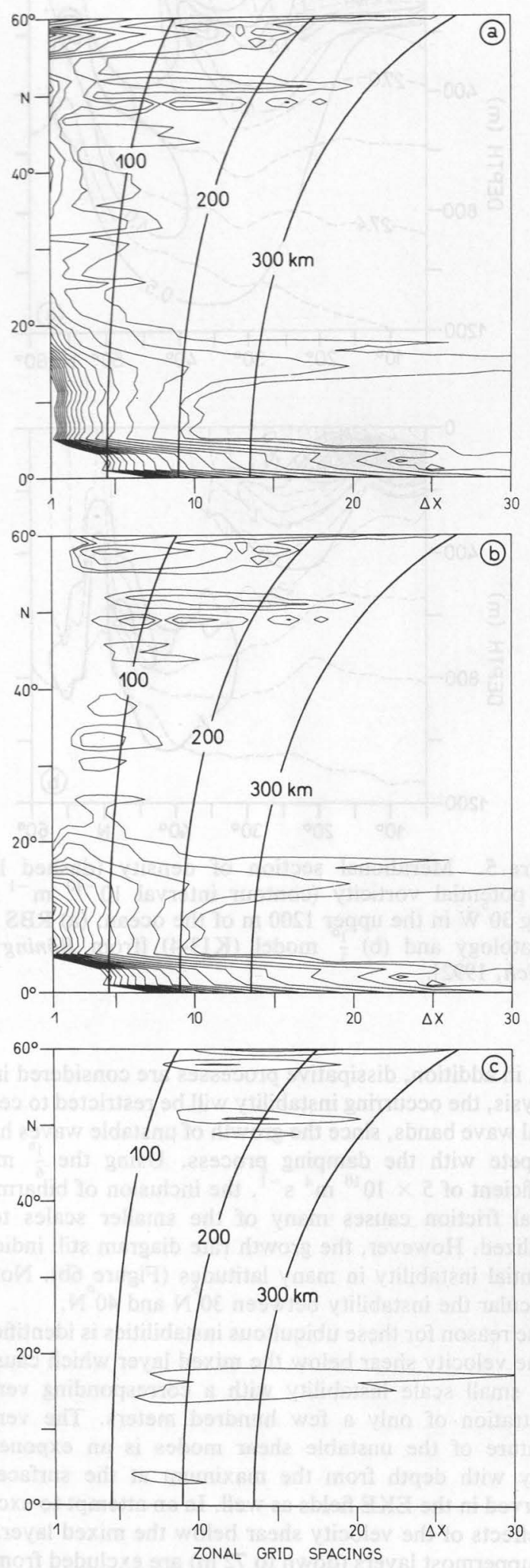

Figure 6. Results from the linearized QG stability analysis, showing perturbation energy increase within 1 day as a function of zonal wavelength and latitude: (a) inviscid, entire water column; (b) including dissipation; and (c) ocean interior only (excluding the mixed layer). The 100-, 200-, and $300-\mathrm{km}$ wavelengths are indicated (heavy lines). indirectly. The ocean below the mixed layer reveals a dominant first baroclinic mode, which is only insignificantly modified by the presence of the velocity shear below the surface. Even in the NAC region, a significant portion of EKE seems to be the result of shear mode instability between the mixed layer and the ocean interior. This is consistent with the decreased scales and the increased variability for the reduced friction in the $\frac{1}{6}^{\circ}$ experiment, where the hydrographic fields and the potential vorticity $q_{0}$ in the interior did not change significantly [see Beckmann et al., 1994]. This instability process is directly related to the vertical velocity shear between the mixed layer (usually the uppermost one or two layers) and the oceanic interior. In the inviscid limit this results in a maximal unstable wave at very small scales, since the involved fluid thickness is relatively small. It is then the role of dissipation to shift the maximum instability toward longer scales.

\subsection{Model Energy Transfer and Turbulent Momentum Fluxes}

Regional energy budgets may help to elucidate the role of fluctuating fields for the general circulation. A calculation of complete energy budgets (including forcing, dissipation, and advection terms) is beyond the scope of the present study. Some insight may be gained, however, by an examination of the eddy-mean flow interaction terms

$$
\begin{gathered}
T_{1}=g \iint \overline{w \rho} d V \\
T_{2}=g \iiint \frac{\overline{u^{\prime} \rho^{\prime}}(\partial \bar{\rho} / \partial x)+\overline{v^{\prime} \rho^{\prime}}(\partial \bar{\rho} / \partial y)}{d \tilde{\rho} / d z} d V \\
T_{3}=-g \iiint \overline{w^{\prime} \rho^{\prime}} d V
\end{gathered}
$$

and

$$
T_{4}=-\iiint \overline{u^{\prime} u^{\prime}} \frac{\partial \bar{u}}{\partial x}+\overline{u^{\prime} v^{\prime}}\left(\frac{\partial \bar{v}}{\partial x}+\frac{\partial \bar{u}}{\partial y}\right)+\overline{v^{\prime} v^{\prime}} \frac{\partial \bar{v}}{\partial y} d V
$$

where the overbar represents a time average and the prime the deviation from that mean. Model field correlations are only available for $\theta$ (instead of $\rho$ ), and thus a proportionality of the form $\rho=\rho_{o}(1-\alpha \theta)$ was assumed. The horizontally averaged density $\tilde{\rho}$ was used to calculate the potential energy components. Here $T_{1}$ represents the transfer from the mean kinetic to the mean potential energy reservoir, $T_{2}$ the conversion from mean potential to eddy potential energy, $T_{3}$ the flux from eddy potential to eddy kinetic energy, and $T_{4}$ the effect of the Reynolds stresses on the fluctuating part of the kinetic energy. Positive values of $T_{2}$ are commonly seen as an indication of $\mathrm{BCI}$, and positive $T_{4}$ suggests the occurrence of barotropic instability (BTI).

Because of small-scale spatial variability in the terms, regional budgets are not robust, and we will focus on averages over large areas. Figure 7 shows the energy transfer terms evaluated in the central northeast Atlantic subdomain from $20^{\circ}$ to $40^{\circ} \mathrm{W}$ and between the equator and $60^{\circ} \mathrm{N}$ for the top $1000 \mathrm{~m}$. Both kinetic energy components are similar to the ones obtained for the subtropical gyre in the "box model" of Böning and Budich [1992]; the potential energies, 
however, are much larger as a result of the more realistic mean density $\tilde{\rho}$ in the Atlantic model. The main energy input in the central North Atlantic is through time-mean wind and buoyancy forcing. The seasonal components of both the wind and the buoyancy forcing are small relative to dissipation of EKE and EPE, respectively. On average, both BCI and BTI are present in this region.

Transfer terms involving the vertical velocity $\left(T_{1}\right.$ and $\left.T_{3}\right)$ are locally strongly modified by the upwelling and downwelling caused by flow over rough bottom topography, which might actually mask (or fake) a coherent signal. Therefore only $T_{2}$ and $T_{4}$ are examined for a systematic energy transfer as an indication of BCI and BTI, respectively. Figure 8 shows the meridional dependence of these terms, averaged over the top $1000 \mathrm{~m}$ and between $30^{\circ} \mathrm{W}$ and $35^{\circ} \mathrm{W}$. The upper ocean "feels" a positive $T_{2}$ in only two regions: the tropics south of $8^{\circ} \mathrm{N}$ and the NAC between $46^{\circ} \mathrm{N}$ and $52^{\circ} \mathrm{N}$. The resulting curve is very similar to the one obtained from experiment K13-3, which did not include a mechanism for wind-induced deepening of the mixed layer. It appears that the presence or absence of a mixed layer has only a small effect on the energy cycle in the central part of the model Atlantic. Nonzero values of $T_{4}$ can be found in the NAC frontal area with positive values (BTI) at the southern flank and an even larger area of negative values (inverse BTI) north of the jet.

The role of mesoscale variability in meridional (vertically and zonally integrated) momentum transport has received only a little attention in previous large-scale model studies. The mean momentum flux through a zonal/vertical cross section may be decomposed into a mean and a fluctuating part,

$$
\begin{aligned}
\iint \overline{v u} a \cos \phi d \lambda d z & =\iint \overline{v u} a \cos \phi d \lambda d z \\
& +\iint \overline{v^{\prime} u^{\prime}} a \cos \phi d \lambda d z
\end{aligned}
$$

These quantities, averaged over our standard central North Atlantic subdomain, are shown in Figure 9. They are expected to be important in frontal jet regions where they can

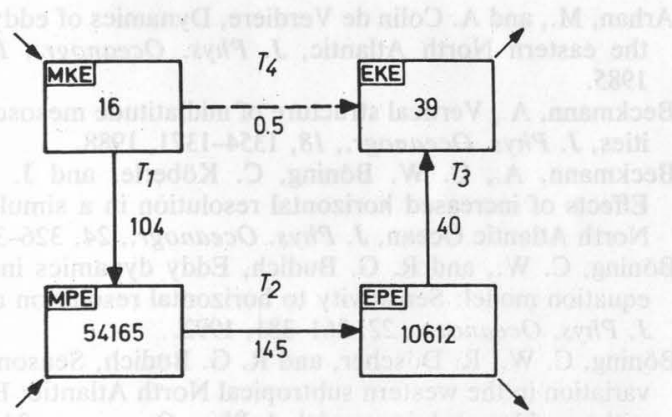

Figure 7. Energy components (in square centimeters per square second) and interaction terms (in $10^{-6} \mathrm{~cm}^{2} \mathrm{~s}^{-3}$ ) in the $\frac{1}{6}^{\circ}$ model for the subdomain $20^{\circ} \mathrm{W}$ to $40^{\circ} \mathrm{W}$ and between the equator and $60^{\circ} \mathrm{N}$. The terms were averaged vertically from the surface to $1000 \mathrm{~m}$ depth. The dashed arrow tail between MKE and EKE indicates that $T_{4}$ only represents the effect of the eddy-mean flow interaction on the fluctuating kinetic energy component, not on the mean.
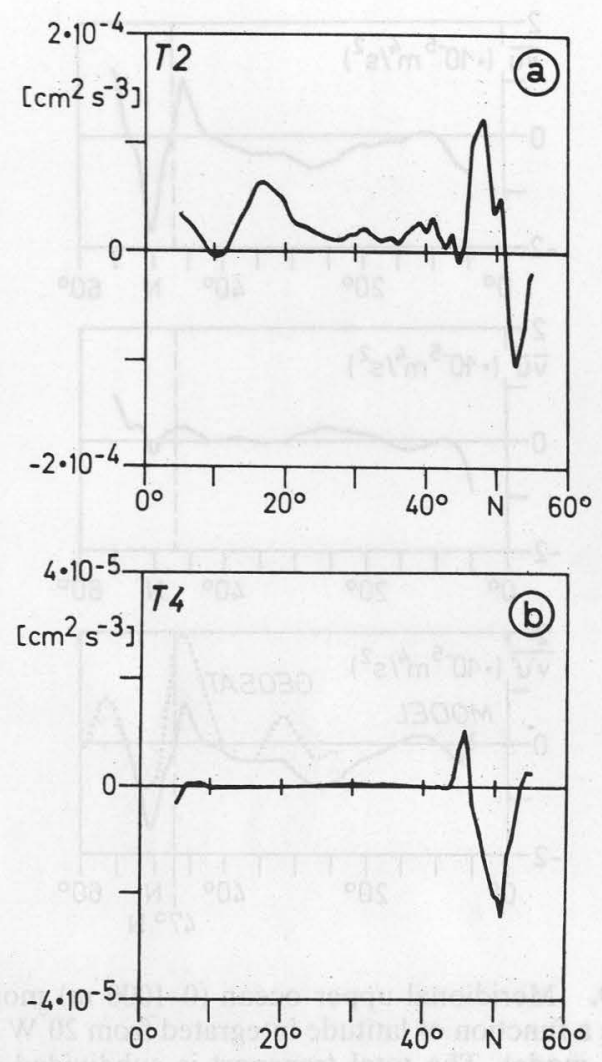

Figure 8. Meridional dependence of the energy transfer terms $T_{2}$ and $T_{4}$ in the $\frac{1}{6}^{\circ}$ model along $30 \mathrm{~W}$ for the uppermost $1000 \mathrm{~m}$ of the ocean.

be responsible for cross-frontal fluxes and lateral redistribution of momentum. This is clearly the case for the mean position of the NAC at $47^{\circ} \mathrm{N}$ which is characterized by an along-front convergence of zonal momentum. The contribution from the fluctuating velocities dominates the time-mean part and provides the main mechanism for the momentum flux in the subpolar front region. This can be described as a "negative viscosity," where the momentum flux is against the mean gradients. Further south, however, there is a broad southward eddy flux of momentum, which is inconsistent with observations. In the tropics we find indications of a convergence of momentum, due to a strong mean part.

To validate these results, the off-diagonal component of the Reynolds stress tensor $\overline{u^{\prime} v^{\prime}}$ is compared against Geosat observations, estimated from objectively analyzed data on a regular grid (Figure 9, dotted line). The altimeter measurements confirm the picture of a converging momentum flux at zonal frontal zones in the central and eastern North Atlantic. There is a remarkable agreement in the position of the subpolar front, while a similar structure of converging momentum flux is missing in the AC region of the model. The drifter results in this area are ambiguous and not included in the figure.

In summary, the mean state and the variability fields in the three central North Atlantic frontal zones (NAC, AC, and NEC) are closely interrelated: while the climatological frontal zones are created by external forcing, fluctuations of the frontal jets produce eddies, which in turn tend to generate a momentum flux convergence (inverse BTI), helping to maintain the front. 

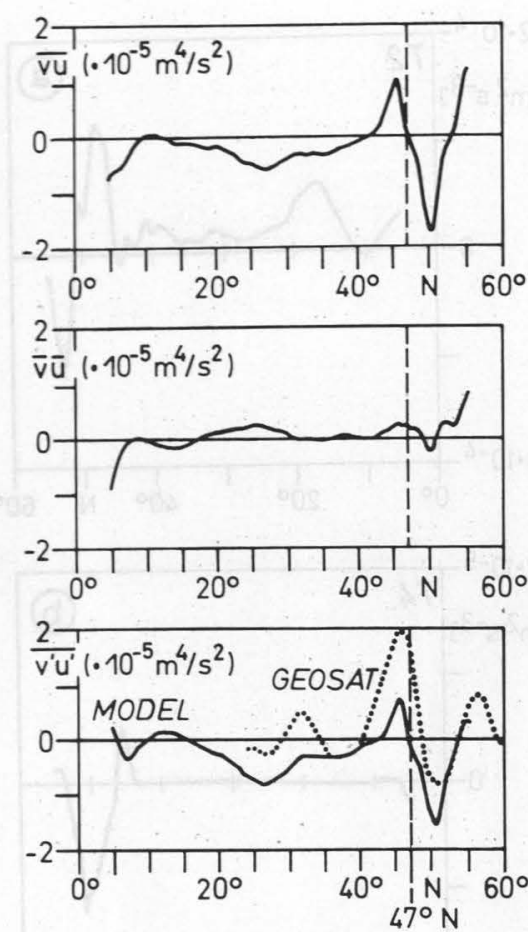

Figure 9. Meridional upper ocean $(0-1000 \mathrm{~m})$ momentum fluxes as a function of latitude integrated from $20^{\circ} \mathrm{W}$ to $40^{\circ} \mathrm{W}$ in the $\frac{1}{6}^{\circ}$ model. The total transport is subdivided into the mean and eddy-related contributions. The observed Reynolds stress terms $\overline{u^{\prime} v^{\prime}}$ along $30^{\circ} \mathrm{W}$ from Geosat are added (dotted line).

\section{Conclusions}

In this study we reexamine the sources and effects of near-surface eddy variability in the central North Atlantic. Climatological data and model results from different versions of the CME model were combined with a new analysis of the extensive Kiel drifter data set and Geosat altimeter data. At the same time the influence of horizontal model resolution $\left(\frac{1}{3}^{\circ}\right.$ versus $\left.\frac{1}{6}^{\circ}\right)$ and lateral dissipation on the representation of mesoscale variability in the CME models was quantified.

1. The variability maps from climatology, Geosat, and surface drifters give the consistent picture of three mainly zonally oriented bands of high near-surface variability related to the North Equatorial Current, the Azores Current, and the North Atlantic Current. Deficiencies in the geographical distribution of the model variability are found in the Azores Current Frontal Zone and in the zonal penetration of the North Atlantic Current, neither of which can be attributed to insufficient model resolution. Both deficiencies contribute to the very weak model variability in large parts of the eastern basin, which was already noted by Treguier [1992].

2. The hydrographic structure in all three areas of high variability suggests that baroclinic instability is the prime source for the fluctuations in these regions. The reversal of potential vorticity gradients with depth provides the necessary condition for a net energy flux from the mean flow to the fluctuations. In addition, we found indications for systematic shear mode instability in the near-surface layers of the model, both from a quasi-geostrophic stability analysis and an inspection of the energy transfer terms. The results suggest that dissipation must be the limiting factor for the background level of eddy kinetic energy in the numerical simulations. Also, given the crude nature of the currently used mixed layer representation, one might wonder how more complete mixed layer physics would alter these results.

In the context of eddy generation mechanisms, preliminary results from experiment K13-5 with daily forcing (based on ECMWF data) need to be mentioned. They show that high-frequency wind forcing does not necessarily lead to a higher variability in the eastern basin. The daily wind fluctuations mainly cause a strong inertial wave response in the two uppermost layers of the model but seem to have small effects on EKE below the Ekman layer in the main thermocline. When taken together with the observed banded nature of EKE, the omission of the high-frequency components in the wind forcing does not seem to account for the major deficiencies in the model's EKE distribution.

3. Eddy length scales as deduced from sea surface height fields decrease northward and follow a linear relationship with the first baroclinic Rossby radius $R_{1}$. The model results show that this can be successfully simulated. There is no clear indication that the resolution of $R_{1}$ is necessary to get a realistic representation of eddy scales: the $\frac{1}{6}^{\circ}$ model results are very close to the Geosat results even in the subpolar gyre, where $R_{1}$ is not resolved. Scales of the extratropical temperature anomaly field at $1000 \mathrm{~m}$ are found to be directly proportional to $R_{1}$.

4. Eddy fluxes of heat are found to be downgradient across the frontal zones, but the momentum fluxes act to build up and strengthen the fronts. These competing processes create the quasi-permanent structure of the frontal zones in the central and eastern North Atlantic.

Acknowledgments. This study was supported by the Deutsche Forschungsgemeinschaft (DFG Sonderforschungsbereich SFB 133) and the Bundesministerium für Forschung und Technologie (BMFT grants $07 \mathrm{KFT} 45$ and $07 \mathrm{KFT} 460$ ). Model calculations were conducted on the CRAY-2 of the German Climate Research Center (DKRZ) in Hamburg and on the CRAY X-MP of Kiel University.

\section{References}

Arhan, M., and A. Colin de Verdiere, Dynamics of eddy motions in the eastern North Atlantic, J. Phys. Oceanogr., 15, 153-170, 1985.

Beckmann, A., Vertical structure of midlatitude mesoscale instabilities, J. Phys. Oceanogr., 18, 1354-1371, 1988.

Beckmann, A., C. W. Böning, C. Köberle, and J. Willebrand, Effects of increased horizontal resolution in a simulation of the North Atlantic Ocean, J. Phys. Oceanogr., 24, 326-344, 1994.

Böning, C. W., and R. G. Budich, Eddy dynamics in a primitive equation model: Sensitivity to horizontal resolution and friction, J. Phys. Oceanogr., 22, 361-381, 1992.

Böning, C. W., R. Döscher, and R. G. Budich, Seasonal transport variation in the western subtropical North Atlantic: Experiments with an eddy-resolving model, J. Phys. Oceanogr., 21, 1271-1289, 1991a.

Böning, C. W., R. Döscher, and H.-J. Isemer, Monthly mean wind stress and Sverdrup transports in the North Atlantic: A comparison of the Hellerman-Rosenstein and Isemer-Hasse climatologies, J. Phys. Oceanogr., 21, 221-239, $1991 \mathrm{~b}$.

Brügge, B., and J. Dengg, Differences in drift behavior between drogued and undrogued satellite-tracked drifting buoys, J. Geophys. Res., 96, 7249-7263, 1991.

Bryan, F. O., and W. R. Holland, A high resolution simulation of 
the wind and thermohaline-driven circulation in the North Atlantic Ocean, in Parametrization of Small-Scale Processes: Proceedings Aha Huliko'a Hawaiian Winter Workshop, edited by P. Müller and D. Anderson, pp. 99-115, University of Hawaii, Honolulu, 1989.

Bryan, F. O., C. W. Böning, and W. R. Holland, On the mid-latitude circulation in a high-resolution model of the North Atlantic, $J$. Phys. Oceanogr., in press, 1994.

Bryan, K., A numerical method for the study of the circulation of the world ocean, J. Comput. Phys., 4, 347-376, 1969.

Charney, J. G., and M. Stern, On the stability of internal baroclinic jets in a rotating atmosphere, J. Atmos. Sci., 19, 159-172, 1962.

Cox, M. D., A primitive equation three-dimensional model of the ocean, Tech. Rep. 1, 250 pp., Geophys. Fluid Dyn. Lab. Ocean Group, Princeton Univ., Princeton, N. J., 1984.

Dantzler, H. L., Jr., Potential energy maxima in the tropical and subtropical North Atlantic, J. Phys. Oceanogr., 7, 512-519, 1977.

Emery, W. J., On the geographical variability of the upper level mean and eddy fields in the North Atlantic and North Pacific, $J$. Phys. Oceanogr., 13, 269-291, 1983.

Emery, W. J., W. G. Lee, and L. Magaard, Geographic and seasonal distributions of Brunt-Väisälä frequency and Rossby radii in the North Pacific and North Atlantic, J. Phys. Oceanogr., 14, 294-317, 1984.

Gill; A. E., J. S. A. Green, and A. J. Simmons, Energy partition in the large scale ocean circulation and the production of mid-ocean eddies, Deep Sea Res., 21, 499-528, 1974.

Hellerman, S., and M. Rosenstein, Normal monthly wind stress over the world ocean with error estimates, J. Phys. Oceanogr., 13, 1093-1104, 1983.

Isemer, H. J., and L. Hasse, The Bunker Climate Atlas of the North Atlantic Ocean, vol. 2, Air-Sea Interactions, 256 pp., SpringerVerlag, New York, 1987.

Keffer, T., The ventilation of the world's ocean: Maps of the potential vorticity field, J. Phys. Oceanogr., 15, 509-523, 1985.

Krauss, W., and R. H. Käse, Mean circulation and eddy kinetic energy in the eastern North Atlantic, J. Geophys. Res., 89, $3407-3415,1984$.

Krauss, W., R. Döscher, A. Lehmann, and T. Viehoff, On eddy scales in the eastern and northern North Atlantic Ocean as a function of latitude, J. Geophys. Res., 95, 18,049-18,056, 1990.

LeTraon, P. Y., M. C. Rouquet, and C. Boissier, Spatial scales of mesoscale variability in the North Atlantic as deduced from Geosat data, J. Geophys. Res., 95, 20,267-20,285, 1990.

Levitus, S., Climatological atlas of the world ocean, NOAA Prof. Pap. 13, 173 pp., U.S. Govt. Print. Office, Washington, D. C., 1982.

McDowell, S., P. B. Rhines, and T. Keffer, North Atlantic potential vorticity and its relation to the general circulation, J. Phys. Oceanogr., 12, 1417-1436, 1982.

Mercier, H., and A. Colin de Verdiere, Space and time scales of mesoscale motions in the eastern North Atlantic, J. Phys. Oceanogr., 15, 171-183, 1985.

Richardson, P. L., Eddy kinetic energy in the North Atlantic from surface drifters, J. Geophys. Res., 88, 4355-4367, 1983.

Robinson, M., R. Bauer, and R. Schroeder, Atlas of the North Atlantic-Indian Ocean Monthly Mean Temperatures and Mean Salinities of the Surface Layer, Department of the Navy, Washington, D. C., 1979.

Semtner, A. J., and R. M. Chervin, Ocean general circulation from a global eddy-resolving model, J. Geophys. Res., 97, 5493-5550, 1992.

Stammer, D.; and C. W. Böning, Mesoscale variability in the Atlantic Ocean from Geosat altimetry and WOCE high resolution numerical modeling, J. Phys. Oceanogr., 22, 732-752, 1992.

Stammer, D., and J. D. Woods, Isopycnic potential vorticity atlas of the North Atlantic Ocean-Monthly mean maps, Rep. 165, 108 pp., Ber. Inst. für Meereskunde Kiel, Kiel, Germany, 1987.

Treguier, A. M., Kinetic energy analysis of an eddy resolving, primitive equation model of the North Atlantic, J. Geophys. Res., 97, 687-701, 1992.

A. Beckmann, Alfred-Wegener-Institute for Polar and Marine Research, Am Handelshafen 12, D-27570 Bremerhaven, Federal Republic of Germany:

C. W. Böning and B. Brügge, Institut für Meereskunde, Düsternbrooker Weg 20, D-24105 Kiel, Federal Republic of Germany.

D. Stammer, Department of Earth, Atmospheric and Planetary Sciences, Massachusetts Institute of Technology, Cambridge, MA 02139-4397.

(Received June 1, 1993; revised April 25, 1994; accepted June 23, 1994.) 